\title{
The Development of Prediction Model for Failure Force of Damaged Reinforced-Concrete Slender Columns
}

\author{
Lovorka GOTAL DMITROVIĆ, Željko KOS, Yvgenii KLIMENKO
}

\begin{abstract}
Any damage to the column and in particular the reducing of the cross section, requires steps to repair the columns, taking temporary measures in the form of taking part of the load and / or reducing the useful load on the damaged column. In order for these measures to be applied more adequately and at the same time preventing adverse effects, it is necessary to define the actual impact of certain cross-sectional damage on the bearing capacity. In this paper the conceptual, mathematical and system dynamics models of the effect of the force on damaged reinforced-concrete column were developed, according to the real values of the failure force. The prediction model is adaptable and it can also be used for the other length slender, the other angle of damage or the depth of damage. The methods of modelling and conceptualization of such situations contribute significantly to protection of architectural heritage. In addition, the economic component of the system should also be taken into consideration. The developed adaptive model allows setting the optimal parameters of the model according to the needs.
\end{abstract}

Keywords: case study; damaged reinforced-concrete columns; failure force; Ishikawa diagram; prediction model; system dynamics

\section{INTRODUCTION}

Majority of the buildings built around the middle of the last century are now in use, even after the expiration of the projected life span regulated through legal norms. It is necessary to devote particular importance to the reinforced-concrete columns, because of the further carrying out of the full projected function and in particular the load-bearing structure of the building. Long life span of the buildings built throughout the history has been provided by the oversized massive wall constructions. It is clear that such massiveness does not exist in buildings constructed in the last century which are built with reinforced-concrete columns. In addition to carrying out the basic load function, the task of column is to allow the best usability of the space in which it is located. That is why the columns are designed with optimum dimensions in conjunction with the quality of concrete and reinforcement, and also taking into account the cost of fabrication.

Any damage to the column and in particular the reducing of the cross section, requires steps to repair the columns, taking temporary measures in the form of taking part of the load and / or reducing the useful load on the damaged column. In order for these measures to be applied more adequately and at the same time preventing adverse effects, it is necessary to define the actual impact of certain cross-sectional damage on the bearing capacity. According to investigations of undamaged pile samples $[10,11]$ after breakdown, a localized type of damage occurs, approximately at the centre of the column, "wedge shaped" shape, depth of $1 / 4$ to $1 / 2$ horizontal section, the length of damage is $20-30 \%$ of the total column length.

This work is based on damaged, slender reinforced concrete columns of rectangular cross-section, where the damage was in the middle third of the height of the column, varying from insignificant damage on the protective layer to the damage with the depth of half the columns cross section. The remaining strength of the damaged reinforced concrete columns was determined by experimental research on reinforced concrete column models in laboratory conditions, and after the collection and processing of data, models were developed to investigate the legality of the behaviour of damaged reinforced concrete column at stress.

Developing model with the research methods of gathering and analysing data and their storage and data access, have significantly enhanced the laboratory methods and their reports. The model was developed in order to gain the information on damage to slender reinforced-concrete rectangular columns. The input variables were used according to the results of the experiment. What is more, the model is adaptable and can also be used for other columns or for other damages. The methods of modelling and conceptualization of such situations contribute significantly to civil engineering. In addition, the economic component of the system should also be taken into consideration. The developed adaptive model allows setting the optimal structure of the model according to the needs and working environment.

\section{MATERIALS AND METHODS}

\subsection{Test Forms}

When selecting the size and the material as well as the loads of the test forms - columns, it is necessary to achieve a functional resemblance to the reinforced concrete columns on the structures, and the test forms are made of concrete $\mathrm{C} 25 / 30$, with longitudinal bars of reinforcement B500, $4 \times 10 \mathrm{~mm}$ and forks B360, $6 \mathrm{~mm} / 15 \mathrm{~cm}(/ 10 \mathrm{~cm}$ at both ends of the test pattern).

The geometric specifications of the reinforced concrete column and the way of fixing its ends, so-called edge conditions, largely determine the area of the columns slenderness. The edge conditions were selected in such a way that the length of the curvature was equal to the length of the test pattern.

Due to the greater impact on the deflection deformations in the direction of the greater moment of inertia, the eccentricity of the action of the axial force of the $1 / 4$ height of section is determined in the same direction as a very unfavourable load case, that is, at the half of the section of the column where damage is present. In the direction of the smaller moment of inertia of the cross section, the position of the axial force action is determined without eccentricity because the impact of the damage on 
the bending column, especially in the direction of the lower moment of inertia, is noticeable.

The final selection of the geometric size of the test elements follows the slenderness analysis. According to European standards (EC-2, EN) [1] columns are considered short and calculation is not required according to theory of the $2^{\text {nd }}$ order if the increase of the bending moment determined by the 1 st order theory due to deformation is not greater than $10 \%$. This is fulfilled when the following condition is met:

$$
\lambda \leq 25(\omega+0.9) \cdot\left(2-\frac{M_{01}}{M_{02}}\right)
$$

where: $\omega=\frac{A_{s} \cdot f_{y d}}{A_{c} \cdot f_{c d}}$; if $A_{s}$ is unknown, $\omega=0.1$ is taken; $A_{s}$ - surface area of steel in a column cross section; $\lambda$ Slenderness coefficient of the column (slenderness); $M_{01}$, $M_{02}$ - momentum of $1^{\text {st }}$ order on the ends - if momentum is 0 , ratio is 1.0 .

Slenderness check of the reinforced-concrete columns 100, 175 and $275 \mathrm{~cm}$ long, with $20 \times 12 \mathrm{~cm}$ cross section surface area.

$\lambda=\frac{l_{0}}{i} \leq \lambda_{\max }$

where: $l_{0}$ - element (column) bending length; $i=\sqrt{\frac{I}{A_{c}}}$ the inertia radius in the direction of lower bending resistance; $I$ - inertia momentum; $A_{c}$ - cross section surface area.

For all test elements, a cross-sectional area of $20 \times 12$ $\mathrm{cm}$ was selected. Three lengths of test elements were selected: 100, 175 and $275 \mathrm{~cm}$.

By including the basic parameters of the selected elements, the slenderness for certain lengths is obtained: for $l=1.0 \mathrm{~m} ; \lambda=28.87$, for $l=1.75 \mathrm{~m} ; \lambda=50.52$ and for $l$ $=2.5 \mathrm{~m} ; \lambda=72,17$, which for the length of the element of $1,0 \mathrm{~m}$ is very close to the boundary value, while for the length of the elements of 1,75 and 2,5 $\mathrm{m}$ the slenderness is greater than the limit value $\lambda_{\max }=29,61$. Consequently, it can be concluded that test elements of $1.75 \mathrm{~m}$ and $2.5 \mathrm{~m}$ length have slenderness greater than the boundary and a calculation according to theory of the $2^{\text {nd }}$ order is required and such reinforced-concrete columns are considered slender

\subsection{Geometry Shape Variation Factors}

The geometry of the test elements is modelled with the planning matrix (Tab. 1) with three basic variants of the geometric shape: $X_{1}$ - the length of the test form (height of reinforced-concrete model columns 100,175 and $275 \mathrm{~cm}$ ), $X_{2}$ - angle of the damage-defect of the elements cross section $\left(0^{\circ}, 30^{\circ}\right.$ and $\left.60^{\circ}\right)$ and the depth of cross-sectional damage-defects of the test elements $(20,60$ and $100 \mathrm{~mm})$.

The cross-sectional damage in all reinforced concrete column models lies exactly at the centre of the model height in length of $40 \mathrm{~cm}$. Fig. 1 shows a cross section of the test element with a median depth $(60 \mathrm{~mm})$ and a median angle $\left(30^{\circ}\right)$ of cross-sectional damage.

Table 1 Planning matrix basic elements

Table 1 Planning matrix basic elements
\begin{tabular}{|c|c|c|c|}
\hline & $x_{1}(\mathrm{~m})$ & $x_{2}\left({ }^{\circ}\right)$ & $x_{3}(\mathrm{~mm})$ \\
\hline-1 & 1 & 0 & 20 \\
\hline 0 & 1,75 & 30 & 60 \\
\hline+1 & 2,5 & 60 & 100 \\
\hline
\end{tabular}

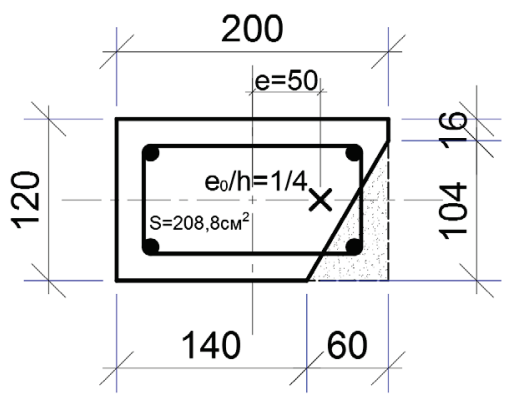

Figure 1 The cross section of the test element

\subsection{The Conceptual Model, the Mathematical Model and the System Dynamics Model}

Ishikawa diagrams (cause-and-effect diagrams) show the causes of a specific effect [5]. Use of the Ishikawa diagram is quality defect prevention. This Cause and Effect analysis is based on diagram technique and pushes you to consider all possible causes of a problem, rather than just the ones that are most obvious [6]. Ishikawa diagrams discover the root of a problem and allow you to manage it. The diagram has a cause side (left) and the effect side (right). For each main cause specific factors are identified. This is done by asking a series of questions "Why" and using correlation methods between two causes (entities).Variables (entities) have attributes (lower order variables). System dynamics enables us to understand the structure and dynamics of complex systems nonlinear behaviour. This is also a rigorous modelling method that enables us to build formal computer simulations of complex systems. [12]. The system dynamics model was created using the Powersim Constructor programme v. 2.51 .

\section{EXPERIMENTAL TESTING}

Experimental testing was carried out in laboratory conditions at Tehnobeton d.d. in Varaždin. For the experiment implementation, a metal cage of Hidroelektra d.d. from Zagreb was used to test the compressive strength of the reinforced concrete elements. The cage consisted of nine vertical metal rods $\varnothing 50 \mathrm{~mm}$ instead of which, due to insufficient rods length, certified geotechnical anchor $\varnothing 32$ mm (R32N), with stretch strength $280 / 360 \mathrm{kN}$, two and three meters long with the original screws and fittings was used.

Metal plates were mounted on the bottom and on top of the cage with diameter of $60 \mathrm{~cm}$ and thickness of 120 $\mathrm{mm}$. Simple static check with the safety coefficient 4 showed that the tense strain durability of the cage is 630 $\mathrm{kN}(F=280 \times 9=2520 / 4=630 \mathrm{kN})$. For the load generator, a hydraulic press with a load capacity of $3000 \mathrm{kN}$ was used. 
At the ends of the test elements, metal caps were mounted $200 \mathrm{~mm}$ in height, $20 \mathrm{~mm}$ thick. The eccentric load action was achieved by inserting metal plates of 120 $\times 100 \times 10 \mathrm{~mm}$ at the bottom of the metal caps, and to the half of the cross section where the test elements are damaged. The deflection length was equal to the length of the test element, which was achieved by poor torsion of the metal cap screws through the elastic holes, enabling the displacement of up to $5 \mathrm{~mm}$ of the two sides of metal caps in the case of bending test elements at the ends.

Bending or deflection of the test elements was measured in the direction of the eccentric force of $1 / 4$ of the cross section height in the direction of the $x$ axis, which in most of the test elements was the direction of action of a greater inertia momentum of the cross section and in the direction of the axis $y$ for which there was no initial eccentric action of axial force. Two measuring instruments with $0.01 \mathrm{~mm}$ precision were mounted on the half and onefourth of the height of the test elements, and the observation was performed after every $50 \mathrm{kN}$ axial force increase. Fig. 2 shows the test element (000) with measuring points and a reinforcement scheme.

The test plan (Tab. 2) included testing of 23 reinforced concrete elements with modelled damages according to the planning matrix described in point 2.2. The test elements were burdened by the action of eccentric axial force, gradually increasing uniformly until the breakdown of the element, ie until the loss of bearing capacity. The force slowly, always at the same speed, increased linearly in periods of $50 \mathrm{kN}$. After each $50 \mathrm{kN}$ magnification, the force remained at the reached load level for 10 minutes.
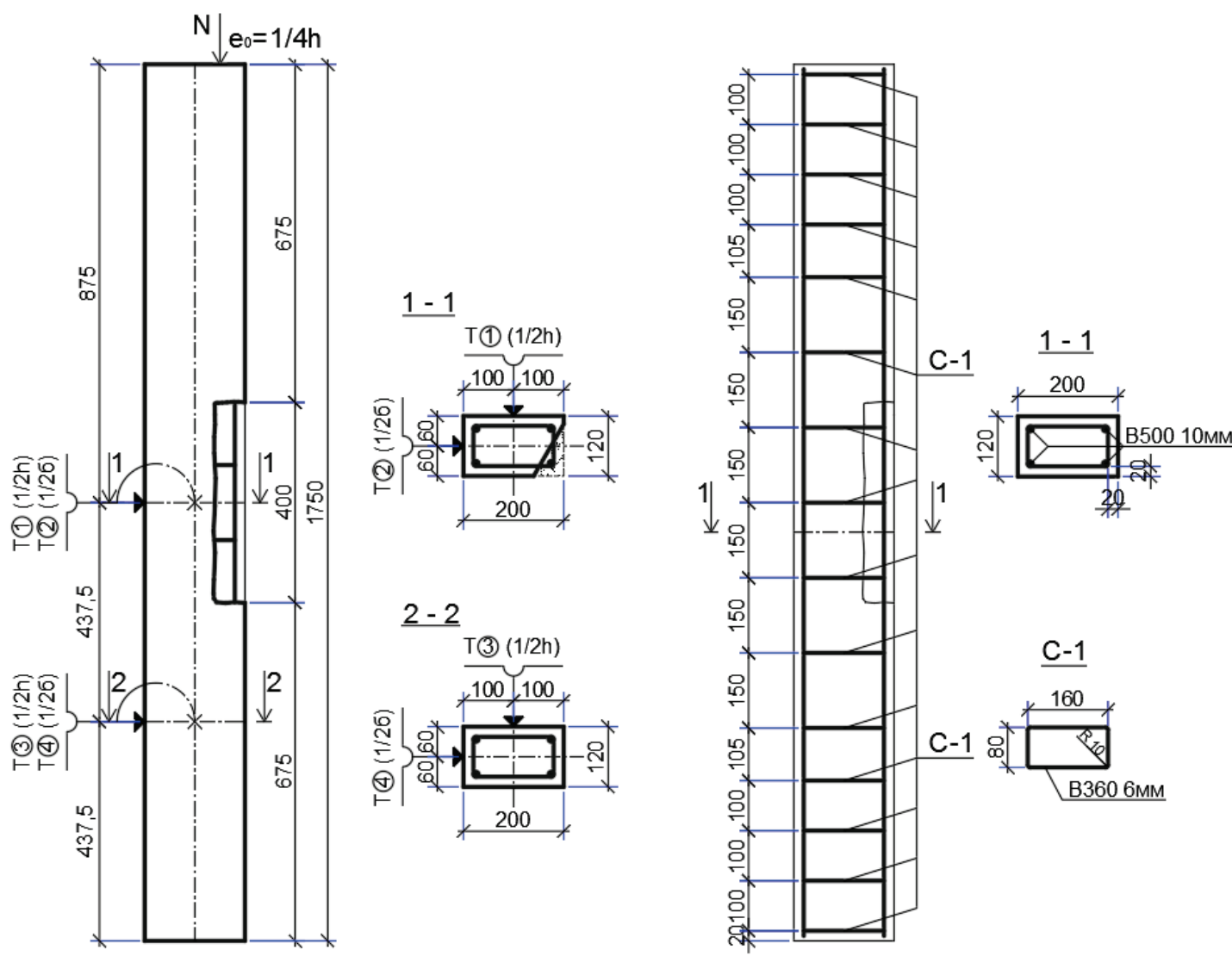

Figure 2 Measuring points of the test element $(000)$ and a reinforcement scheme

Table 2 Test plan

\begin{tabular}{|c|c|c|c|c|c|c|c|c|c|}
\hline \multirow{2}{*}{ Column models } & \multicolumn{9}{|c|}{ Column height $(\mathrm{cm})$} \\
\hline & \multicolumn{3}{|c|}{100} & \multicolumn{3}{|c|}{175} & \multicolumn{3}{|c|}{250} \\
\hline Angle of the damage $\left(^{\circ}\right)$ & \multicolumn{3}{|c|}{ Depth of the damage $\mathrm{mm}$} & \multicolumn{3}{|c|}{ Depth of the damage $\mathrm{mm}$} & \multicolumn{3}{|c|}{ Depth of the damage $\mathrm{mm}$} \\
\hline & 20 & 60 & 100 & 20 & 60 & 100 & 20 & 60 & 100 \\
\hline 0 & $\begin{array}{c}\mathrm{K}_{9} \\
(-1-1-1)\end{array}$ & & $\begin{array}{c}\mathrm{K}_{8} \\
(-1-1+1)\end{array}$ & & $\begin{array}{l}\mathrm{K}_{12}-\mathrm{K}_{21} \\
(0-10)\end{array}$ & & $\begin{array}{c}\mathrm{K}_{4} \\
(+1-1-1)\end{array}$ & & $\begin{array}{c}\mathrm{K}_{3} \\
(+1-1+1)\end{array}$ \\
\hline 30 & & $\begin{array}{c}\mathrm{K}_{10} \\
\left(\begin{array}{ccc}-1 & 0 & 0\end{array}\right)\end{array}$ & & 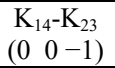 & $\begin{array}{l}\mathrm{K}_{15}-\mathrm{K}_{19} \\
\left(\begin{array}{lll}0 & 0 & 0\end{array}\right)\end{array}$ & $\begin{array}{c}\mathrm{K}_{13}-\mathrm{K}_{22} \\
\left(\begin{array}{ll}0 & 0 \\
0\end{array}\right)\end{array}$ & & $\begin{array}{c}\mathrm{K}_{5} \\
\left(\begin{array}{lll}+1 & 0 & 0\end{array}\right)\end{array}$ & \\
\hline 60 & $\begin{array}{c}\mathrm{K}_{7} \\
(-1+1-1)\end{array}$ & & $\begin{array}{c}\mathrm{K}_{6} \\
(-1+1+1)\end{array}$ & & $\begin{array}{l}\mathrm{K}_{11}-\mathrm{K}_{20} \\
\left(\begin{array}{lll}0 & 0\end{array}\right)\end{array}$ & & $\begin{array}{c}\mathrm{K}_{2} \\
(+1+1-1)\end{array}$ & & $\begin{array}{c}\mathrm{K}_{1} \\
(+1+1+1)\end{array}$ \\
\hline
\end{tabular}

For a comparative analysis of the bearing capacity and deformation of the test elements parameters, in particular the values of the breakdown force, the undamaged test element $\left(\mathrm{K}_{24}\right)$ was $175 \mathrm{~cm}$ long. At the time of suspension failure and breakdown of the test element, the value of the axial force of $530 \mathrm{kN}$ was recorded.

\section{RESULTS AND DISCUSION}

The experimental research which was carried out, fulfilled all the planned tasks of the experiment and the results were recorded in the form of specific numerical values on bearing capacity and bending deformations of 
test elements. The development of visible deformations (concrete cracks, protective layer wrapping, bending of the reinforcement, etc.) was observed and noted, including the character or type of the column break in the moment of the test elements bearing capacity collapse. However, the research of this article is primarily aimed at determining the remaining strength of damaged reinforced concrete columns by a combined method, i.e. residual strength will be determined by mathematical analysis based on the results of the experimental research carried out. Therefore, the results of the experimental research relevant to the selected research method in this article are further illustrated and analysed.

The following table (Tab. 3) shows axial force values at the time of collapse of the test element bearing capacity and their relation to the bearing capacity of the undamaged test element ( $\mathrm{N} / \mathrm{NULT}$ ). The compression strengths of the damaged sections of the $\mathrm{K}_{1}-\mathrm{K}_{23}$ test element and the undamaged section of $\mathrm{K}_{24}$ are also shown.

The analysis of the results shows that the behaviour of the test patterns during the linear application of the eccentric axial force and the character of the breakdown played a significant role in two of the three variance factors - the angle and depth of the damage. The height of the test element, as variation factor ranging from 100 to $250 \mathrm{~cm}$, had a much smaller effect.

The analysis of the results of the research and the mutual comparison of two test elements with identical damage, in which the variable factor was height only, brought to conclusion that the difference in the strength of the test elements was relatively small. Five matching pairs of test patterns with 5 different damage models were analysed, each pair containing 100 and $250 \mathrm{~cm}$ lengths with identical damage per angle and depth of damage $\left(\mathrm{K}_{1}: \mathrm{K}_{6}\right.$, $\mathrm{K}_{2}: \mathrm{K}_{7}, \mathrm{~K}_{3}: \mathrm{K}_{8}, \mathrm{~K}_{4}: \mathrm{K}_{9}$ and $\mathrm{K}_{5}: \mathrm{K}_{10}$ ). Thus the subject analysis of the results of the study showed that deviations in the strength of the test elements, with varying height $(100,175,250 \mathrm{~cm})$, ranged from 0 to $40 \mathrm{kN}$, expressed in percentages $0-12 \%$, which is very small value compared to the highest difference in the strength of the test elements of $340 \mathrm{kN}$, expressed as a percentage of $179 \%$, which is the result of a comparison of the test of the undamaged test element and the element with maximum damage, i.e. element with the variation of the damage to the angle and the depth of " $-1+1$ ", i.e. angle $0^{\circ}$, depth $100 \mathrm{~mm}(h / 2)$.

It is important to note that significant bending is measured in all the test elements in the direction of the $x$ axis, which in most forms is the direction of a greater moment of inertia of the damaged cross section, and it is very easy to conclude that the eccentric position of the axial force per axis $x$ ( $h / 4$ per $x$ axis, 0 per $y$ axis), the main cause for such a bending of the test elements.

For further analysis, the test samples were divided into three groups. The first group contains the test elements $\mathrm{K}_{3}$, $\mathrm{K}_{4}, \mathrm{~K}_{8}, \mathrm{~K}_{9}, \mathrm{~K}_{12}$ and $\mathrm{K}_{21}$, all with maximum damage per angle of damage as the other variable factor $\left(0^{\circ}\right)$ in combination with all depths of damage of the third variable factor $(20,60,100 \mathrm{~mm})$. The $0^{\circ}$ angular damage in accordance with the action of the eccentric axial force contributed to the bending of the test elements in the expected direction on the $x$ axis, of course opposite to the eccentric load vertex and the cross-sectional damage of the test elements.

Table 3 Test elements bearing capacity and damaged cross section compression strength

\begin{tabular}{|c|c|c|c|c|}
\hline Test element № & Test element mark & Breakdown force $\mathrm{kN}$ & $\begin{array}{l}\text { Damaged cross section } \\
\text { compression strength } \mathrm{MPa}\end{array}$ & $\begin{array}{c}\text { Breakdown force and undamaged column } \\
\text { breakdown force ratio }\end{array}$ \\
\hline $\mathrm{K}_{1}$ & $+1+1+1$ & 300 & 14.21 & 0.57 \\
\hline $\mathrm{K}_{2}$ & $+1+1-1$ & 440 & 18.42 & 0.83 \\
\hline $\mathrm{K}_{3}$ & $+1-1+1$ & 210 & 17.50 & 0.40 \\
\hline $\mathrm{K}_{4}$ & $+1-1-1$ & 360 & 16.67 & 0.68 \\
\hline $\mathrm{K}_{5}$ & +100 & 370 & 17.72 & 0.70 \\
\hline $\mathrm{K}_{6}$ & $-1+1+1$ & 300 & 14.21 & 0.57 \\
\hline $\mathrm{K}_{7}$ & $-1+1-1$ & 400 & 16.75 & 0.75 \\
\hline $\mathrm{K}_{8}$ & $-1-1+1$ & 190 & 15.83 & 0.36 \\
\hline $\mathrm{K}_{9}$ & $-1-1-1$ & 330 & 15.28 & 0.62 \\
\hline $\mathrm{K}_{10}$ & -100 & 330 & 15.80 & 0.62 \\
\hline $\mathrm{K}_{11}$ & $0+10$ & 330 & 14.37 & 0.62 \\
\hline $\mathrm{K}_{12}$ & $0-10$ & 230 & 13.69 & 0.43 \\
\hline $\mathrm{K}_{13}$ & $00+1$ & 250 & 15.47 & 0.47 \\
\hline $\mathrm{K}_{14}$ & $00-1$ & 400 & 16.91 & 0.75 \\
\hline $\mathrm{K}_{15}$ & 0000 & 300 & 14.37 & 0.57 \\
\hline $\mathrm{K}_{16}$ & 000 & 400 & 19.15 & 0.75 \\
\hline $\mathrm{K}_{17}$ & 000 & 400 & 19.15 & 0.75 \\
\hline $\mathrm{K}_{18}$ & 000 & 410 & 19.63 & 0.77 \\
\hline $\mathrm{K}_{19}$ & 0000 & 340 & 16.28 & 0.64 \\
\hline $\mathrm{K}_{20}$ & $0+10$ & 460 & 20.03 & 0.87 \\
\hline $\mathrm{K}_{21}$ & $0-10$ & 290 & 17.26 & 0.55 \\
\hline $\mathrm{K}_{22}$ & $00+1$ & 270 & 16.71 & 0.51 \\
\hline $\mathrm{K}_{23}$ & $00-1$ & 380 & 16.07 & 0.72 \\
\hline $\mathrm{K}_{24}$ & $0--$ & 530 & 22.08 & 1 \\
\hline
\end{tabular}

In the second group, test elements with various combinations of medium $\left(30^{\circ}\right)$ and minimal $\left(60^{\circ}\right)$ damage per angle as second variance factor and with medium (60 $\mathrm{mm})$ and maximum $(100 \mathrm{~mm})$ damage per depth as the third variation factor are classified. In addition to the expected bending in the direction of the $x$ axis as in the first group elements, primarily due to the eccentric action of the axial force, the analysis of the results revealed the characteristic bending of the test elements in the axis $\mathrm{y}$ direction, somewhat less properly on the $\mathrm{K}_{1}, \mathrm{~K}_{6}, \mathrm{~K}_{11}$ and $\mathrm{K}_{20}$ test elements with varying factors per angle with minimal damage and with medium and maximum depth of 
damage $\left(60^{\circ}, 60-100 \mathrm{~mm}\right)$. On $\mathrm{K}_{5}, \mathrm{~K}_{10}$ and $\mathrm{K}_{15-19}$ with medium damage of both variance factors $\left(30^{\circ} ; 60 \mathrm{~mm}\right)$, and on the $\mathrm{K}_{13}$ and $\mathrm{K}_{22}$ elements with medium angle and maximum depth of damage $\left(30^{\circ}, 100 \mathrm{~mm}\right)$, almost linear bending of the undamaged side $h$ per axis $y_{i}$ was noted since $40 \%$ of the load was applied until the breakdown of the test elements.

In the third group, the test elements $\mathrm{K}_{2}, \mathrm{~K}_{7}, \mathrm{~K}_{14}, \mathrm{~K}_{23}$ $\left(30-60^{\circ}, 20 \mathrm{~mm}\right)$ were analysed with combinations of minimal depth damage with minimal and medium damage per angle as varying factors. The axial bending deformations were also observed in the axial direction primary due to axial force eccentricity, and in relation to the cross sectional damage, it can be concluded that the damage in combination of angle variation $\geq 30^{\circ}$ and depth of damage of $\leq 20 \mathrm{~mm}$ did not affect the bending deformation of the test elements.

All of the test forms have the constant shape of the undamaged cross section $(20 \times 12 \mathrm{~cm})$ and they are made of concrete C 25/30, with longitudinal bars of reinforcement B500, $4 \times 10 \mathrm{~mm}$ and forks B360, $6 \mathrm{~mm} /$ $15 \mathrm{~cm}$ (/ $10 \mathrm{~cm}$ at both ends of the test pattern) and a model was actually a case study. In the Ishikawa diagrams on the right, as a result, the FAILURE FORCE is shown. Causes are: height of the column and depth and angle of damage (Fig. 3).

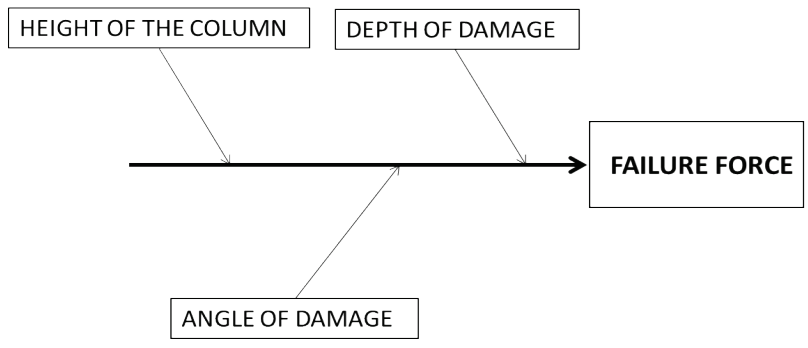

Figure 3 Ishikawa diagram

The function of the angle of damage $\left(x_{1}\right)$ and force $\left(y_{1}\right)$ (Tab. 3) was obtained on a column's height of $175 \mathrm{~cm}$ and a depth of damage of $60 \mathrm{~mm}$ (columns: $\mathrm{K}_{12}, \mathrm{~K}_{21}, \mathrm{~K}_{15}, \mathrm{~K}_{19}$, $\mathrm{K}_{11}, \mathrm{~K}_{20}$ ) (Tab. 1).

Table 3 The angles of damage and failure force

\begin{tabular}{|c|c|c|c|}
\hline \multicolumn{3}{|c|}{ REAL } & FUNCTION \\
\hline Angle of damage $\left(^{\circ}\right)$ & Force $(\mathrm{kN})$ & Columns & Force $(\mathrm{kN})$ \\
\hline 0 & 230 & $\mathrm{~K}_{12}$ & 257.5 \\
\hline 0 & 290 & $\mathrm{~K}_{21}$ & 257.5 \\
\hline 30 & 300 & $\mathrm{~K}_{15}$ & 325 \\
\hline 30 & 340 & $\mathrm{~K}_{19}$ & 325 \\
\hline 60 & 330 & $\mathrm{~K}_{11}$ & 392.5 \\
\hline 60 & 460 & $\mathrm{~K}_{20}$ & 392.5 \\
\hline
\end{tabular}

The function is linear (Fig. 4):

$y_{1}=257.5+2.25 \cdot x_{1}$

Validation shows an $11.587 \%$ deviation, calculated by the coefficient of variation (Tab. 3).

The following test is the influence of the failure force $\left(y_{1}\right)$ from the column height $\left(x_{2}\right)$ (Tab. 4). The sample used was an angle of damage of $30^{\circ}$ and a depth of damage of $60 \mathrm{~mm}$.

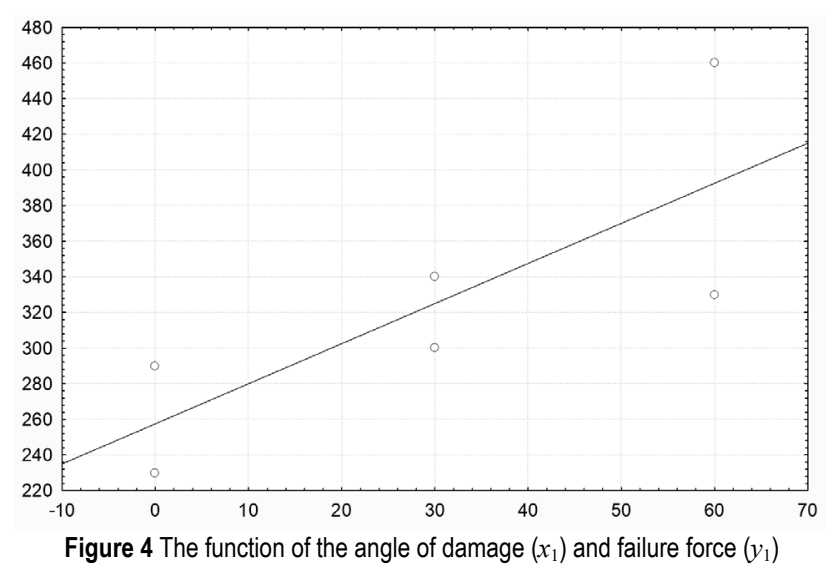

Table 4 The column length and failure force

\begin{tabular}{|c|c|c|c|}
\hline & \multicolumn{2}{|c|}{ REAL } & MODEL \\
\hline Columns & Length $(\mathrm{cm})$ & Force $(\mathrm{kN})$ & Force $(\mathrm{kN})$ \\
\hline $\mathrm{K}_{10}$ & 100 & 330 & 330.22 \\
\hline $\mathrm{K}_{19}$ & 175 & 340 & 340.67 \\
\hline $\mathrm{K}_{5}$ & 250 & 370 & 371.38 \\
\hline
\end{tabular}

The function is polynomial (Fig. 5):

$y_{1}=347.7778-0.3556 \cdot x_{2}+0.0018 \cdot x_{2}^{2}$

Validation shows a $0.212 \%$ deviation, calculated by the coefficient of variation (Tab. 4).

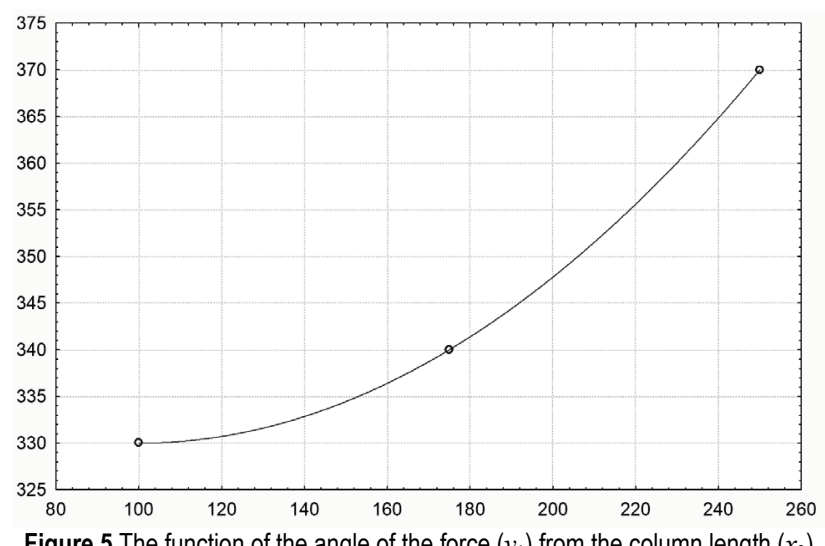

Figure $\mathbf{5}$ The function of the angle of the force $\left(y_{1}\right)$ from the column length $\left(x_{2}\right)$

The last dependence is the influence of force on the depth of damage. To find the function of dependence, a column length of $175 \mathrm{~cm}$ was used, with an angle of damage of $30^{\circ}$. The function of the depth of damage $\left(x_{3}\right)$ and force $\left(y_{1}\right)$ (Tab. 5) was obtained on a column's height of $175 \mathrm{~cm}$ and an angle of the damage of $30^{\circ}$ (columns: $\mathrm{K}_{14}, \mathrm{~K}_{23}, \mathrm{~K}_{13}, \mathrm{~K}_{22}, \mathrm{~K}_{15}-\mathrm{K}_{19}$ ) (Tab. 1).

Table 5 The depth of damage and failure force

\begin{tabular}{|c|c|c|c|}
\hline \multicolumn{3}{|c|}{ REAL } & FUNCTION \\
\hline Depth of damage (mm) & Force $(\mathrm{kN})$ & Columns & Force $(\mathrm{kN})$ \\
\hline 20 & 400 & $\mathrm{~K}_{14}$ & 390.01 \\
\hline 20 & 380 & $\mathrm{~K}_{23}$ & 390.01 \\
\hline 60 & 300 & $\mathrm{~K}_{15}$ & 377.55 \\
\hline 60 & 400 & $\mathrm{~K}_{16}$ & 377.55 \\
\hline 60 & 400 & $\mathrm{~K}_{17}$ & 377.55 \\
\hline 60 & 410 & $\mathrm{~K}_{18}$ & 377.55 \\
\hline 100 & 250 & $\mathrm{~K}_{13}$ & 260.13 \\
\hline 100 & 270 & $\mathrm{~K}_{22}$ & 260.13 \\
\hline
\end{tabular}

The function is polynomial (Fig. 6): 
$y_{1}=356.875+2.3125 \cdot x_{3}-0.0328 \cdot x_{3}^{2}$

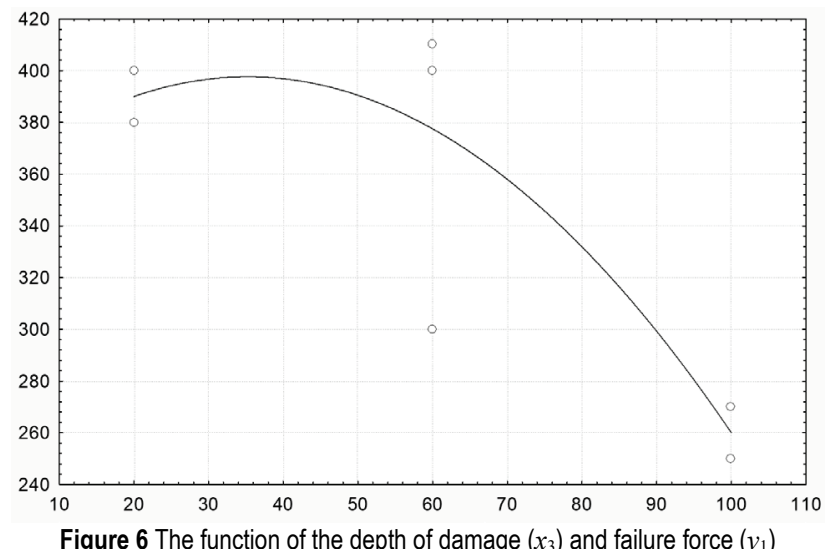

Validation shows a $7.229 \%$ deviation, calculated by the coefficient of variation (Tab. 5). The ratio between $x_{1}$, $x_{2}$ and $x_{3}$ is calculated based on $y=350 \mathrm{kN}$ :

$x_{1}: x_{2}: x_{3}=1: 5: 2$

System dynamics model (Fig. 7) includes functions 3, 4,5 and 6.

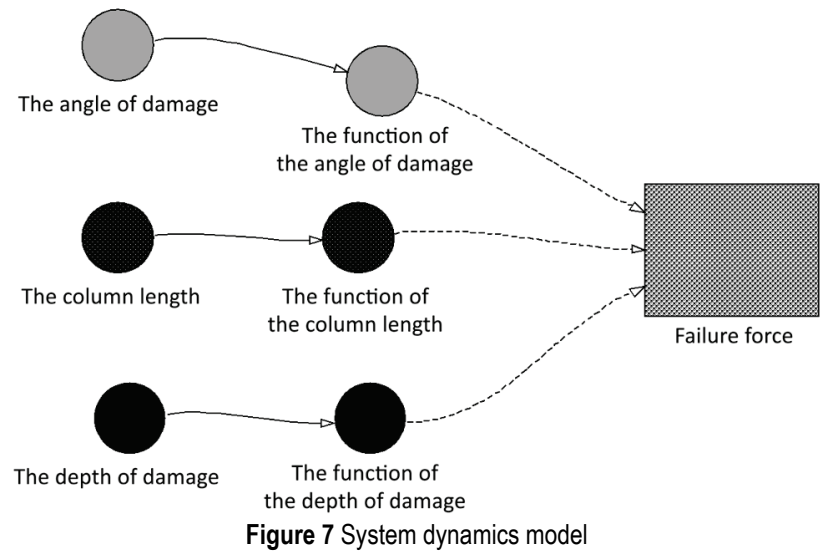

\section{CONCLUSION}

Based on the study and the developed model, prediction model for Failure Force of Damaged Reinforced-Concrete Slender has been designed. Academic literature frequently publishes articles which describe the construction and technological performances for solutions to Damaged Reinforced-Concrete Slender. The development of information technologies with a special emphasis on the research methods of gathering and analysing data and their storage and data access, has significantly enhanced the laboratory methods and their reports [2]. Statistical software tools support many functions of simulation modelling, providing the additional benefit of supporting robust calculations, data analysis, quality assurance, visualization and data sub-setting.

The scientific community [4] has recently highlighted the need for the conceptualization and parameterization of the system model before the construction of the system itself. The model was developed in order to gain the information on failure force of Damaged ReinforcedConcrete Slender. The input variables were used according to the results of the research findings on real columns. What is more, the model is adaptable and can also be used for the length of the column, other angle of damage or the depth of damage. The methods of modelling and conceptualization of such situations contribute significantly to protection of architectural heritage. In addition, the economic component of the system should also be taken into consideration. The developed adaptive model allows setting the optimal parameters of the model according to the needs.

\section{REFERENCES}

[1] Eurocode 2: Design of concrete structures - Part 1: General rules and rules for buildings, European Committee for Standardization, 2001.

[2] Gotal Dmitrović, L., Dušak, V., \& Anić Vučinić, A. (2015). The Development of Conceptual, Mathematical and System Dynamics Model for Food Industry Wastewater Purifying System. JIOS, 39(2), 151-162.

[3] Gotal Dmitrović, L., Dušak, V., \& Milković, M. (2017). Involving Environmental Informatics in Croatian Technical Studies. Tehnički vjesnik, 24(4), 709-715. https://doi.org/10.17559/TV-20160209132849

[4] Huang, G. H. \& Chang, N. B. (2003). Perspectives of Environmental Informatics and Systems Analysis. Journal of Environmental Informatics, 1(1), 1-6. https://doi.org/10.3808/jei.200300001

[5] Ishikawa, K. (1976). Guide to Quality Control, Asian Productivity Organization, UNIPUB.

[5] Jackson, K. Cause and Effect Analysis - Identifying the Likely Causes of Problems, https://www.mindtools.com/ pages/article/newTMC_03.htm

[7] Klymenko, I. \& Orešković, M. (2018). Damaged circular columns: research and calculation. University North and Odessa State Academy of Civil Engineering and Architecture, 169.

[8] Kos, Ž., Gotal Dmitrović, L., \& Klimenko, I. (2017). Developing a model of a strain (deformation) of a damaged reinforced concrete pillar in relation to a linear load capacity. Tehnički glasnik, 11(4), 150-154

[9] Orešković, M., Klymenko, E., Aniskin, A., \& Kozina, G. (2018). Analysis of Damaged Concrete Columns of Circular Cross-Section. Tehnički vjesnik, 25(2), 337-343. https://doi.org/10.17559/TV-20160621085905

[10] Němeček J. (2004). Effect of Stirrups on Behavior of Normal and High Strength Concrete Columns. Acta Polytechnica, 44(5-6). 158-164

[11] Rabie M. (2012) Behavior of R.C Columns with Poor Concrete Strength at Upper Part. Life Science Journal, 9(2). 1159-1165.

[12] Sterman, J. D. (2000). Business Dynamics: Systems Thinking and Modelling for a Complex World, Mc Grow-Hill Higher Education.

[13] Von Bertalanffy, L (1968) General System Theory: Foundations, Development, Applications. George Braziller Inc., New York.

[14] Wasserman, L. (2006) All of Nonparametric Statistics, Springer, New York.

[15] Woodall, W. H. (2000). Controversis and Contradictions in Statistical Process Control. Journal of Quality technology Session, October 12-13. 


\section{Contact information:}

Lovorka GOTAL DMITROVIĆ, PhD, Ass. Prof.

(Corresponding author)

University North,

Križaničeva 31 b, Varaždin, Croatia

E-mail: Igotaldmitrovic@unin.hr

Željko KOS, PhD, lecturer

University North,

Križaničeva 31 b, Varaždin, Croatia

E-mail: zeljko.kos@unin.hr

Yevgenii KLYMENKO, PhD, Full Prof.

Odessa State Academy of Civil Engineering and Architecture,

Didrihsona 4, Odessa, Ukraine

E-mail: klimenkoew57@gmail.com 